\title{
BMJ Open Effect of profit status in facilities on the mortality of patients on long-term haemodialysis: a nationwide cohort study
}

\author{
Sheng-Yu Liu, ${ }^{1}$ Chung-Yi Cheng (D) , ${ }^{1,2,3}$ Mei-Yi Wu, ${ }^{1,3,4}$ Cai-Mei Zheng, ${ }^{1,3,4}$ \\ Chih-Cheng Hsu, ${ }^{5}$ Mai-Szu Wu, ${ }^{1,3,4}$ Yen-Chung Lin (iD) 1,3,6
}

To cite: Liu S-Y, Cheng CY, Wu M-Y, et al. Effect of profit status in facilities on the mortality of patients on long-term haemodialysis: a nationwide cohort study. BMJ Open 2021;11:e045832. doi:10.1136/ bmjopen-2020-045832

- Prepublication history for this paper is available online. To view these files, please visit the journal online (http://dx.doi. org/10.1136/bmjopen-2020045832).

S-YL and M-SW contributed equally.

Received 14 October 2020 Accepted 23 August 2021
Check for updates

(C) Author(s) (or their employer(s)) 2021. Re-use permitted under CC BY-NC. No commercial re-use. See rights and permissions. Published by BMJ.

For numbered affiliations see end of article.

Correspondence to

Dr Yen-Chung Lin;

yclin0229@tmu.edu.tw

\section{ABSTRACT}

Objectives Over the past two decades, debates on whether the profit status of dialysis facilities influences patient prognosis have been popular in the USA. Taiwan is one of the regions with the highest rate per capita of kidney replacement therapy worldwide, but no similar research has been conducted to date. This is the first study to address this issue.

Design This was a nationwide retrospective cohort study based on the Taiwan Renal Registry Data System.

Setting Patients were categorised into two groups based on the profit status (for-profit, not-for-profit (NFP)) of dialysis facilities, with 31350 patients in each group. The patients were followed up from 2005 to 2012.

Participants Patients with uraemia who underwent longterm haemodialysis in private dialysis facilities and public facilities were excluded.

Primary and secondary outcome measures Survival analyses were performed to compare prognosis between the two groups. Adjustments to patients' basic profile, and facilities' geographical distribution, level, and length of ownership were carried out to minimise possible confounding effects.

Results Analysis revealed that NFP dialysis facilities had better outcomes (HR=0.91, 95\% $\mathrm{Cl}(0.89$ to 0.93$)$ ). A favourable effect remains with the adjustment of the facilities' level, geographical distribution ( $\mathrm{HR}=0.89$, $95 \% \mathrm{Cl}(0.86$ to 0.93$))$ or length of ownership ( $\mathrm{HR}=0.95$, $95 \% \mathrm{Cl}(0.89$ to 0.95$))$. Survival analysis based on the geographical distribution and level of facilities was also conducted, which showed better prognosis in medical centres in the six municipalities, whereas worse prognosis was found in local hospitals not located in these municipalities.

Conclusion Our findings suggest that in contemporary settings in Taiwan, treatment at NFP dialysis facilities was associated with a better prognosis. The results should be interpreted with caution since the possibility of residual confounding effects and uncertainty of casual relations exist due to the nature of observational studies.

\section{INTRODUCTION}

Taiwan remains one of the countries with the highest prevalence and incidence of kidney replacement therapy worldwide, ${ }^{1}$ as they
Strengths and limitations of this study

- This study was based on a relatively large sample size from a nationwide database (Taiwan Renal Registry Data System).

- Potential confounding effects of the study were minimised by matching study groups, adjusting for facilities' geographical distribution, level and length of ownership.

- Uncontrolled/residual confounding factors may interfere with the association between the profit status of facilities and patient prognosis due to the observational study design.

- Missing data from facilities' length of ownership limited further adjustment of this study.

- The study results have limited generalisability to other countries on account of different healthcare landscapes and insurance systems.

reached 3480 per million individuals and 504 per million individuals, respectively, in $2017 .^{2}$ The total amount of National Health Insurance (NHI) for patients with uremia who underwent dialysis therapy, including haemodialysis (HD) or peritoneal dialysis, is approximately 62 billion New Taiwanese dollar (or US $\$ 2179$ million), with $8.7 \%-9.2 \%$ of the total health expenditure in Taiwan in $2019 .^{2}$ Therefore, it is vital to determine the factors predicting patients' survival. These factors not only influence patient outcomes, but also impact the cost-effectiveness of HD. Of all the factors, the profit status of a dialysis facility is an important concern. ${ }^{3}$

In the past two decades, there has been debate on whether the profit status of dialysis facilities has an influence on patient mortality. According to a meta-analysis published in 2002 by Devereaux et $a l^{4}$ the pooled estimation demonstrated that private for-profit (FP) dialysis facilities were associated with an increased risk of death (risk 
ratio $=1.08,95 \%$ CI $(1.04$ to 1.13$), \mathrm{p}<0.001)$. Nevertheless, a retrospective analysis of the US Renal Data System (USRDS) by Brooks et a $\tilde{p}$ indicated that no relationship exists between dialysis facilities' profit status and patient survival after adjusting for the two-stage least squares variant of instrumental variable estimation with the relative proximity of facilities to the patient's residence as the instrument. Additionally, a retrospective study comparing Foley et $a l$ s study, ${ }^{6}$ featuring more recent patient data from the Medicare database between 1998 and 2003, with that of Devereaux et al's study, with patients enrolled between 1973 and 1997, showed no significant difference in patient mortality between $\mathrm{FP}$ and not-for-profit (NFP) facilities (adjusted HR=1.02, 95\% CI (0.99 to 1.06), $\mathrm{p}=0.143$ ). Finally, a retrospective analysis of the USRDS by Brunelli $e t a l^{7}$ concluded that no difference was observed in mortality and hospitalisation rates between FP and NFP dialysis facilities when appropriate statistical adjustments were made, which emphasised the 'provider-level' approach by adding potential confounders such as facility's geographical location, length of facility ownership, vascular access at first dialysis session and pre-dialysis nephrology care into their analysis.

Despite the abundance of HD patients in Taiwan, few studies are available on this topic. However, this study is largely influenced by the health policy, ${ }^{8}$ insurance, structure and distribution of dialysis facilities. The NHI system of Taiwan covers nearly the entire population of Taiwan and a broad range of medical services, including HD. Patients only need to pay a registration fee of approximately US $\$ 3$ for each dialysis course. The fee is similar across different levels of facilities, and no specific referral system restricts patients from directly seeking dialysis treatment in high-level facilities. Under a unified payment system in Taiwan, it is a good opportunity to uncover the actual effect of ownership that might be confounded by the complex setting of the healthcare market in the USA. ${ }^{9}$ Our research aimed to evaluate whether the profit status of dialysis facilities affects patient mortality. We assume that the effect of profit status among HD centres on mortality or survival benefit in Taiwan is minimal. Further analysis should be performed to ensure that the possible confounding factors are taken into account.

\section{METHODS}

\section{Setting and participants}

Patients registered in the Taiwan Renal Registry Data System (TWRDS) from 2005 to 2012 were enrolled $(\mathrm{N}=115535)$. In Taiwan, all dialysis facilities have been obligated to upload patient information quarterly since $1987 .{ }^{10}$ Information included patients' biochemical profiles, history, dialysis location and timing. After excluding patients treated with peritoneal dialysis $(\mathrm{N}=9232)$, that shift between different dialysis modalities $(\mathrm{N}=4661)$, who underwent $\mathrm{HD}$ at public facilities $(\mathrm{N}=20609)$ and with missing biochemical/comorbidity profile $(\mathrm{N}=2570)$, the remaining 76483 patients were

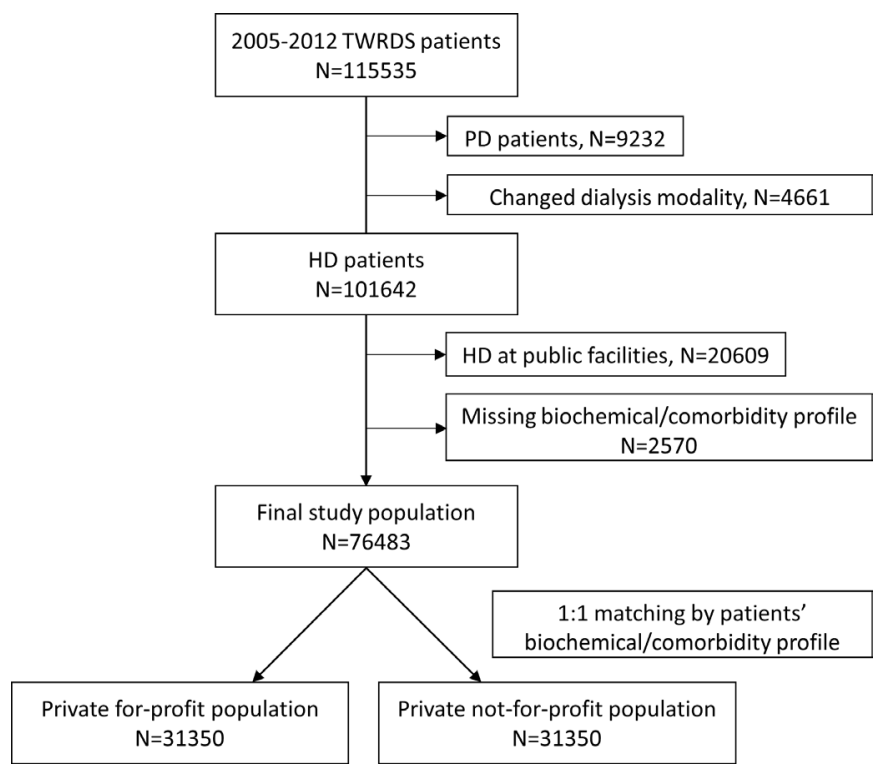

Figure 1 Flow chart of the patient selection process. HD, haemodialysis; PD, peritoneal dialysis; TWRDS, Taiwan Renal Registry Data System.

included in our study (figure 1). If the patient underwent dialysis in multiple facilities, we chose the facility where the patient visited most frequently.

\section{Patient and public involvement}

No patient involved.

\section{Grouping}

By facilities' ownership and profit status

The profit status of dialysis facilities was divided into two groups, including 'private FP' and 'private NFP,' whereas public facilities were excluded. A facility was regarded as private when it is not established by government authorities, government-owned enterprises or public schools. ${ }^{11}$ Furthermore, a facility was considered private NFP if it is established or operated by a medical foundation. ${ }^{11}$ NFP facilities are required to contribute no less than $20 \%$ of revenue on research, training, health education, community service or charity. As compensation, NFP facilities are exempt from corporate tax, land and property taxes, and personal income tax. A reduction in the corporate tax is also offered. ${ }^{9}$

\section{By facilities' level and geographical distribution}

Facilities were divided into eight categories as a correction factor, according to four levels of medical facilities designated by the Taiwanese Ministry of Health and Welfare (medical centre, metropolitan hospital, local community hospital and clinic) and two types of geographical distribution in Taiwan (six special municipalities (SMC) or not). The Ministry of Health and Welfare of Taiwan holds hospital accreditation yearly and categorises medical facilities into four levels. A medical centre should be a teaching and research hospital with over 500 beds and 23 medical specialties. Metropolitan hospitals should be teaching hospitals with more than 300 beds and most 
medical specialties (including pathology, anaesthesiology, radiology and rehabilitation). Local community hospitals should have no more than 100 beds and provide general/ emergency healthcare services. Clinics are not subject to hospital accreditation, which are relatively small in size. ${ }^{12}$ Special municipalities are defined as regions with populations of not less than 1250000 and have special requirements in their political, economic, cultural and metropolitan development. ${ }^{13}$ Currently, there are six municipalities in Taiwan. Information concerning the level of the dialysis facility and its geographical distribution can be found in the TWRDS lists of dialysis facilities. The dialysis facility's length of ownership was also used as a correction factor. Information was collected through an online search of official websites or telephone interviews. The facilities were divided into four groups: group 1 (established for $0-5$ years), group 2 ( $6-10$ years), group 3 (11-20 years) and group 4 ( $\geq 20$ years).

\section{Statistical analysis}

Descriptive statistics were expressed as mean $\pm \mathrm{SD}$ for continuous variables and proportions for categorical variables. One-way analysis of variance or the Kruskal-Wallis test was used for the analysis of differences between continuous variables, and the nominal variables were compared using the $\chi^{2}$ test. Kaplan-Meier analysis was performed using the log-rank test. The level of significance was set at 0.05 , two-tailed for all tests. A Cox regression model for survival analysis was used to estimate the HRs of all-cause mortality in HD patients. The primary endpoint of our study was all-cause mortality. If a patient switched to other dialysis modalities or received kidney transplant during follow-up period, the patient would be censored. An individual was considered deceased if he or she was lost to follow-up in the TWRDS based on the complete national coverage provided by the NHI policy for all kidney replacement therapy expenditures in Taiwan. All descriptive and multivariate analyses were performed using the SPSS software (V.17.0) for Windows V.XP (SPSS) and SAS V.9.1 (SAS Institute).

\section{Survival analysis based on the profit status of the facilities}

Survival analysis was performed to compare the HRs between the FP and NFP groups. Propensity score matching by patient age, sex and biochemical/comorbidity profile (table 1) was conducted before survival analysis, resulting in 31350 patients in each group. With reference to the studies by Brunelli $e$ a $a l^{7}$ our research was carried out with four models, each correcting different parameters. Crude data compared the HR between FP and NFP without correction. Model 1 additionally corrects for age and sex. Models 2 and 3 further correct coronary artery disease (CAD), myocardial infarction (MI) and diabetes mellitus (DM) rates in the population. Furthermore, model 2 adds the geographical distribution and level of dialysis facilities as a correction factor, and model 3 adds the length of ownership as a correction factor.
Table 1 Baseline characteristics between the for-profit and not-for-profit groups after matching

Type of facilities by profit status

\begin{tabular}{llll} 
Variable & For-profit & Not-for-profit & P value \\
\cline { 2 - 3 } Number & 31350 & 31350 & \\
\hline Age (years) & $62.3 \pm 13.5$ & $62.2 \pm 13.5$ & 0.66 \\
\hline Male (\%) & $15831(50)$ & $15764(50)$ & 0.59 \\
\hline DM (\%) & $16136(51)$ & $16128(51)$ & 0.95 \\
\hline HTN (\%) & $13799(44)$ & $13459(43)$ & $<0.01$ \\
\hline CHF (\%) & $4803(15)$ & $4585(15)$ & $<0.05$ \\
\hline LVH (\%) & $4556(15)$ & $4328(14)$ & $<0.01$ \\
\hline CVA (\%) & $2012(6)$ & $2038(7)$ & 0.67 \\
\hline CAD (\%) & $3815(12)$ & $3762(12)$ & 0.52 \\
\hline MI (\%) & $948(3)$ & $1027(3)$ & 0.07 \\
\hline HTN drugs (\%) & $18475(59)$ & $18274(58)$ & 0.1 \\
\hline HD duration & $3.55 \pm 2.61$ & $3.55 \pm 2.61$ & 0.99 \\
(years) & & & \\
\hline Albumin (g/dL) & $3.75 \pm 0.40$ & $3.74 \pm 0.41$ & $<0.01$ \\
\hline Hct (\%) & $31.09 \pm 3.40$ & $31.05 \pm 3.15$ & 0.13 \\
\hline Ca (mg/dL) & $9.18 \pm 0.71$ & $9.18 \pm 0.69$ & 0.33 \\
\hline P (mg/dL) & $4.84 \pm 1.12$ & $4.83 \pm 1.11$ & 0.37 \\
\hline ALK-P ( $\mu / L)$ & $128.4 \pm 97.1$ & $128.5 \pm 100.5$ & 0.91 \\
\hline i-PTH (pg/mL) & $226.9 \pm 184.0$ & $225.5 \pm 175.6$ & 0.32 \\
\hline
\end{tabular}

ALK-P, alkaline phosphatase; $\mathrm{Ca}$, calcium; $\mathrm{CAD}$, coronary artery disease; CHF, chronic heart failure; CVA, cerebrovascular accident; DM, diabetes mellitus; Hct, haematocrit; HD, haemodialysis; HTN, hypertension; i-PTH, intact parathyroid hormone; LVH, left ventricular hypertrophy; MI, myocardial infarction; P, phosphate.

Survival analysis based on facilities' level and geographical distribution

Survival analysis was also performed based on the eight categories of facilities' level and geographical distribution without consideration of the profit status to evaluate the possible confounding effect of these categories.

\section{RESULTS}

\section{Survival analysis based on profit status}

Baseline characteristics between groups

After matching, there were 31350 patients in each group (FP and NFP). Most baseline characteristics were not significantly different between the groups, except for the prevalence of hypertension, congestive heart failure, left ventricular hypertrophy and albumin level (table 1).

Model 1

The follow-up period was 96 months (2005-2012). Both crude data and model 1 showed significantly favourable outcomes $(\mathrm{p}<0.0001)$ for the NFP group, with HRs of 0.93 and 0.91, respectively. Figure 2 shows the Kaplan-Meier survival curve of the crude data (table 2). 


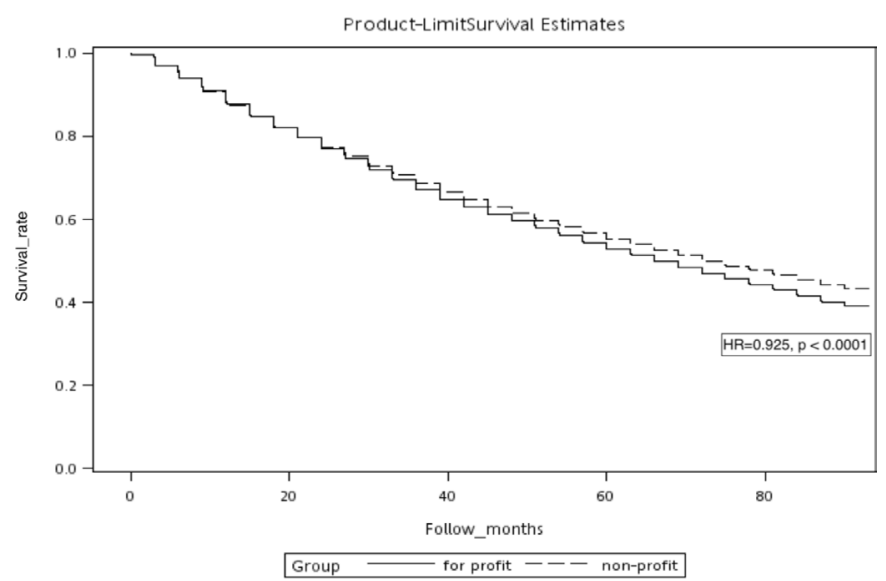

Figure 2 The Kaplan-Meier survival curve in HD patients. The survival rate in the for-profit group (approximately $8.75 \%$ ) was decreased compared with that in the not-for-profit control group $(p<0.0001)$. HD, haemodialysis.

\section{Model 2}

Data show significantly favourable outcomes $(\mathrm{p}<0.0001)$ for the NFP group with an HR of 0.89 (table 3).

\section{Model 3}

Data show a significantly favourable outcome $(p<0.0001)$ for the NFP group with an HR of 0.95 (table 4).

\section{Survival analysis based on facilities' level and geographical distribution}

\section{Baseline characteristics}

Without matching, most parameters in the baseline characteristics showed significant differences between the eight groups. Of note, there were several patients in the SMC group at every level of the dialysis facility. The difference is most apparent in the medical centres (34783 vs 2311) and clinics (10 0192 vs 31450 ), and the influence of this difference on the FP and NFP outcomes will be discussed later in this article (table 5).

\section{Survival analysis}

Survival analyses with adjustments for age, sex, CAD, MI and DM were also performed to compare the impact of the facility level and geographical distribution on patient prognosis. The clinic SMC was designated as the reference group. Trends for better outcomes were observed at the medical centre level, whereas worse outcomes were observed in metropolitan hospitals and local hospitals. Non-significant $p$ values were observed in the medical centre not SMC (NSMC) and clinic NSMC, indicating that the outcome is similar to that of clinic SMC (table 6).

\section{DISCUSSION}

In summary, our results revealed that private NFP dialysis facilities have better patient outcomes than private FP facilities. The favourable effect remains with the adjustment of the facilities' level, geographical distribution or length of ownership.

The possible reasons why NFP and FP facilities have different outcomes have been discussed extensively in previous studies. ${ }^{414-16}$ By definition, FP facilities are owned by investors or shareholders. They usually distribute part of their profits directly to owners and focus on increasing shareholder wealth. In contrast, NFP facilities are owned by members (communities, religious organisations, nongovernmental organisations, universities, etc) to fulfil certain missions (providing health services, teaching or research). Revenue should be used for their stated mission and cannot be distributed to the members of the organisation. ${ }^{16}$ Theoretically, FP facilities result in greater efficiency if there are no barriers to entering the market and there is an observable and measurable outcome. ${ }^{16-18}$ Nevertheless, numerous barriers exist (eg, high capital investment, technology, faculty training, regulation and certification), whereas the outcomes are hardly visible to customers (patients). The barriers to market, asymmetrical information, risk and the uncertain nature of the healthcare industry make it prone to market failure. ${ }^{19}$ In a meta-analysis by Devereaux et $a l,{ }^{20}$ NFP hospitals are associated with higher payments for care, which indicates the shortcoming of FP facilities in terms of efficiency. To make matters worse, FP facilities are often faced with economic challenges. Shareholders expect 10\%-15\% returns on their investments, ${ }^{14}$ and taxes may account for $5 \%-6 \%$ of the total expenses. ${ }^{21} \mathrm{FP}$ facilities must generate these profits and pay taxes while making an effort to provide the same quality of care as NFP facilities that are free of these excessive expenses. ${ }^{4}$ In a healthcare system in which funding and resources are relatively fixed, as with the NHI in Taiwan, the FP facility may try to cut off other forms of spending to generate more profit. Although both business models ought to be confronted with costings on doing audit, ongoing training and purchasing medical supplies, there are several reasons that could result in the better efficiency of NFP facilities. First, due to the

Table 2 Adjustments for age and sex (model 1)

\begin{tabular}{llllllll}
\hline & Crude & & & & Adjusted \\
\cline { 2 - 3 } Group & HR & $\mathbf{9 5 \%} \mathbf{C l}$ & P value & & HR & $\mathbf{9 5 \%} \mathbf{C l}$ & P value \\
\hline For-profit & Reference & & & & Reference \\
$\quad$ Not-for-profit & 0.93 & 0.9 to 0.95 & $<0.0001$ & 0.91 & 0.89 to 0.93 & $<0.0001$ \\
Age (increase per year old) & 1.04 & 1.04 to 1.05 & $<0.0001$ & 1.05 & 1.04 to 1.05 & $<0.0001$ \\
\hline Sex (male) & 1.1 & 1.07 to 1.12 & $<0.0001$ & 1.21 & 1.18 to 1.24 & $<0.0001$ \\
\hline
\end{tabular}


Table 3 Adjustments for age, sex, CAD, MI, DM, geographical distribution and facility level (model 2)

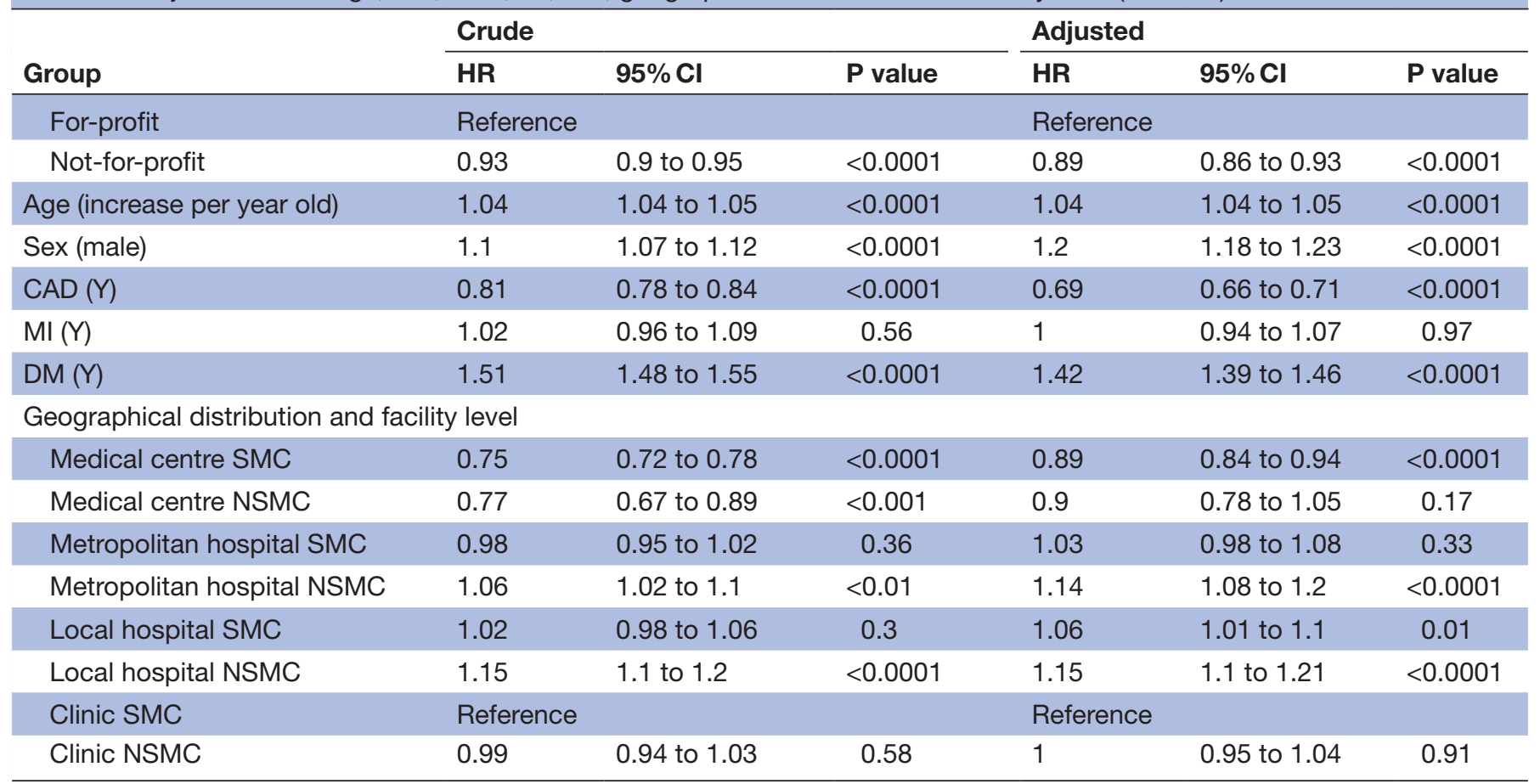

CAD, coronary artery disease; DM, diabetes mellitus; MI, myocardial infarction; NSMC, not six municipalities; SMC, six municipalities; Y, yes.

relatively larger scale of NFP facilities (table 7), economies of scale could be achieved. Facilities of larger scale could reduce the proportion on these expenditure by setting up standard operation procedures. Discounts may be provided by outsourcing training company or medical supply company. Second, according to the regulations in Taiwan, ${ }^{11}$ NFP facilities are exempt from about $20 \%$ of costings on tax while no less than $20 \%$ of revenue on research, training, health education, community medical service or charity is required. The expenditure is roughly equal to the surplus from tax exemption. Additionally, NFP hospitals are entitled to receive charitable contributions. Several financial studies comparing NFP and FP hospitals also indicated that financial performance of NFP hospitals was better than FP hospitals. ${ }^{92}$ Possible approaches for FP facilities to reducing expenses are

Table 4 Model 3 with adjustments for age, sex, CAD, MI, DM and establishment of facilities

\begin{tabular}{|c|c|c|c|c|c|c|}
\hline & Crude & & & Adjusted & & \\
\hline Group & HR & $95 \% \mathrm{Cl}$ & $P$ value & HR & $95 \% \mathrm{Cl}$ & $P$ value \\
\hline For-profit & Reference & & & Reference & & \\
\hline $\begin{array}{l}\text { Age (increase per year } \\
\text { old) }\end{array}$ & 1.04 & 1.04 to 1.05 & $<0.0001$ & 1.05 & 1.04 to 1.05 & $<0.0001$ \\
\hline $\operatorname{CAD}(Y)$ & 0.8 & 0.78 to 0.84 & $<0.0001$ & 0.69 & 0.66 to 0.72 & $<0.0001$ \\
\hline $\mathrm{MI}(\mathrm{Y})$ & 1.02 & 0.96 to 1.09 & 0.56 & 0.93 & 0.86 to 1.01 & 0.08 \\
\hline $\mathrm{DM}(\mathrm{Y})$ & 1.51 & 1.48 to 1.55 & $<0.0001$ & 1.45 & 1.4 to 1.49 & $<0.0001$ \\
\hline \multicolumn{7}{|c|}{ Facilities' length of ownership } \\
\hline Group 1 & Reference & & & Reference & & \\
\hline
\end{tabular}

Group 1 (established for 0-5 years), group 2 (6-10 years), group 3 (11-20 years), group 4 ( $\geq 20$ years).

$\mathrm{CAD}$, coronary artery disease; DM, diabetes mellitus; MI, myocardial infarction; Y, yes. 


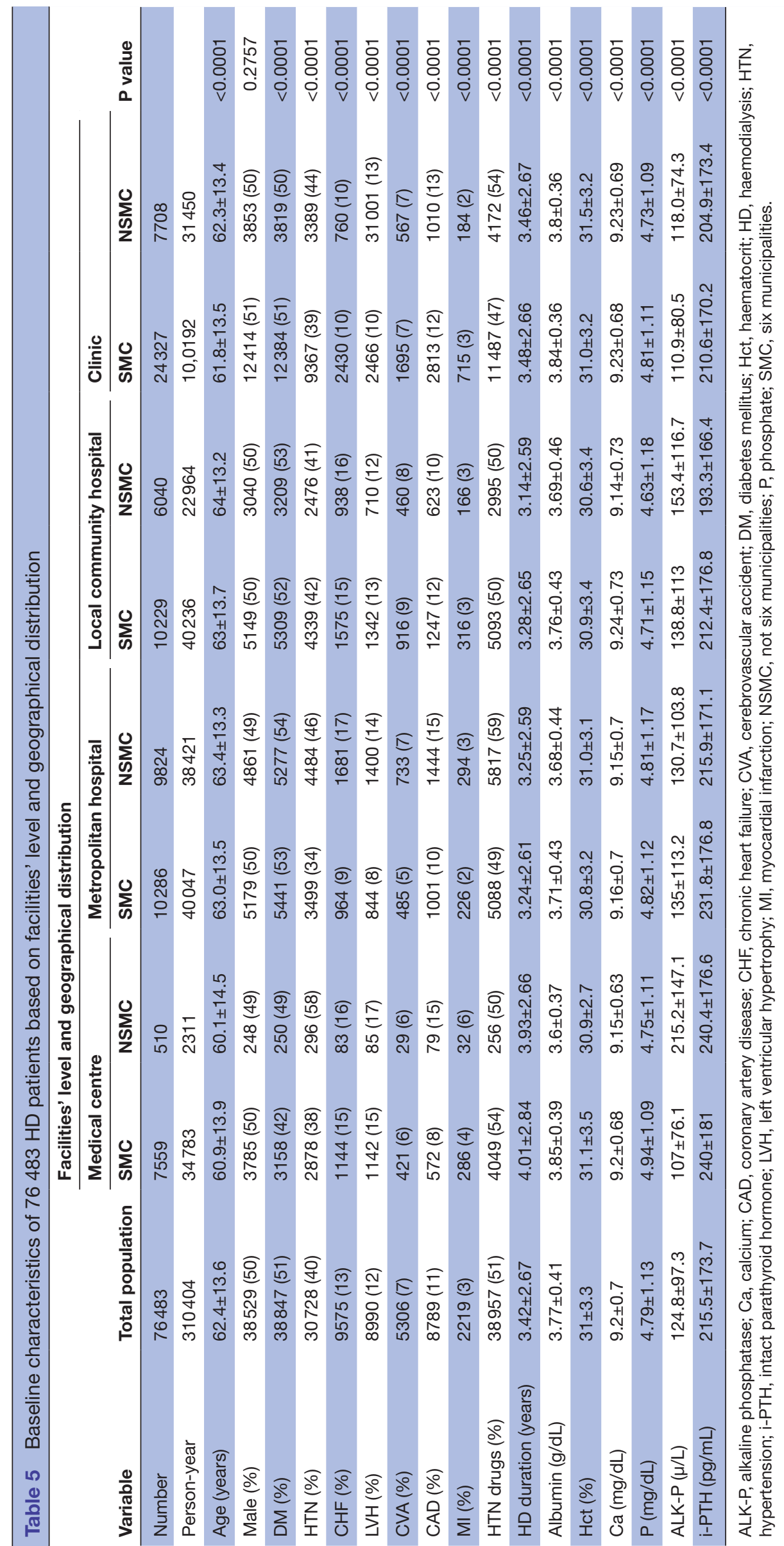


Table 6 Survival analysis based on facilities' level and geographical distribution with adjustments

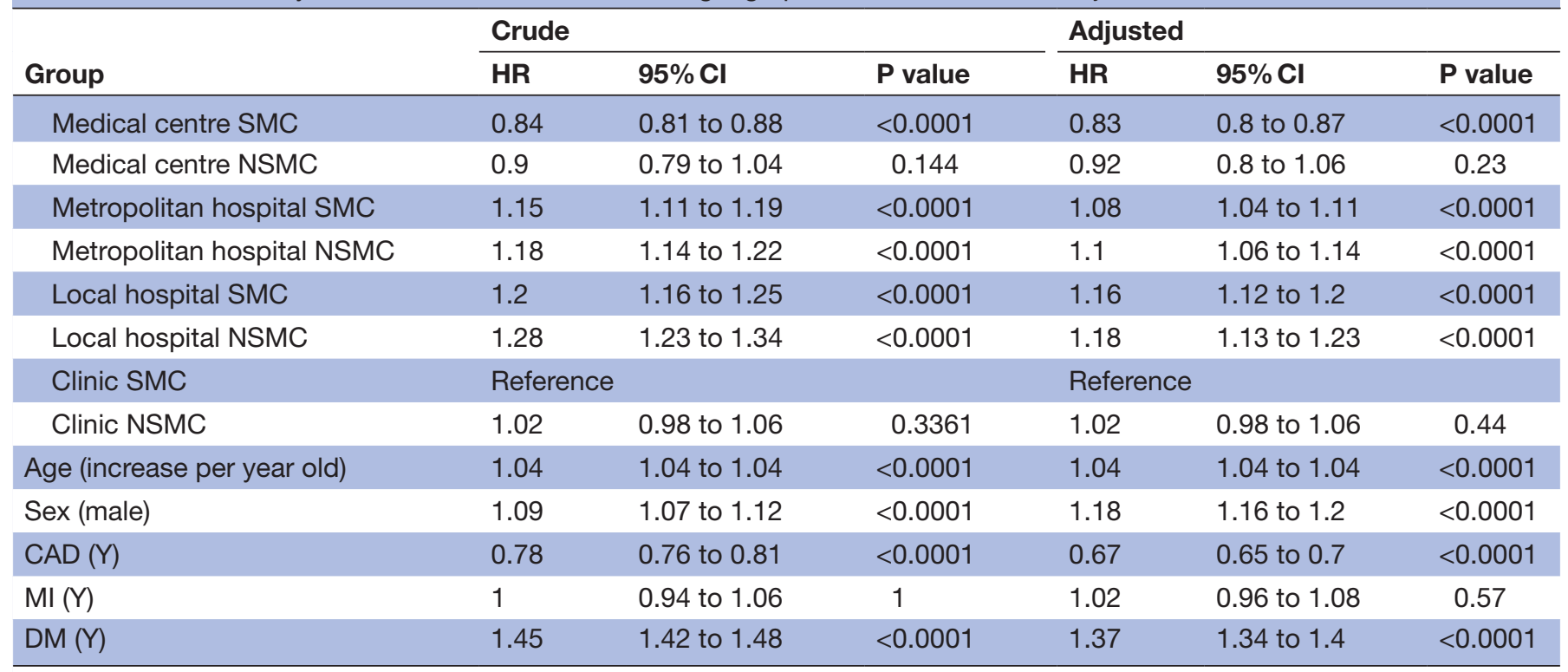

CAD, coronary artery disease; DM, diabetes mellitus; MI, myocardial infarction; NSMC, not six municipalities; SMC, six municipalities; Y, yes.

employing fewer personnel per run and less highly skilled personnel, ${ }^{23} 24$ unwillingness to extend personal dialysis time and using low-performance dialysers. ${ }^{24} 25$ These approaches may also be associated with higher mortality rates in the $\mathrm{FP}$ facilities. ${ }^{25}$

Although our study results are in concordance with those of previous studies, ${ }^{14}$ some confounding factors specific to the setting in Taiwan may exist. Table 7 shows the distribution of the FP and NFP facilities at each level. All medical centres and most metropolitan hospitals are NFP facilities, whereas most clinics are FP facilities. Table 5 shows that the majority of person-year data in medical centres and clinics are contributed by the SMC. Table 6 illustrates that 'medical centre SMC' have the best outcome (HR=0.84, $\mathrm{p}<0.0001$ ), whereas 'clinic SMC' and 'clinic NSMC' show no significant survival benefits $(\mathrm{HR}=$ reference and 1.02 , respectively; $\mathrm{p}=0.3361)$. In conclusion, the NFP population may be affected by the good prognosis of the 'medical centre SMC'; the FP population is less affected by the neutral outcome of the 'clinic SMC'.

Our study had several limitations. First, as mentioned in previous studies, ${ }^{467}$ it is impractical and highly unlikely that any randomised controlled trial will be conducted on this topic. Specifically, current studies unquestionably

\begin{tabular}{lcl}
\hline Table 7 & Level of dialysis facilities and profit status \\
\hline Level & $\begin{array}{l}\text { Private for- } \\
\text { profit }\end{array}$ & $\begin{array}{l}\text { Private not-for- } \\
\text { profit }\end{array}$ \\
\hline Medical centre & 0 & 14 \\
Metropolitan hospital & 7 & 41 \\
Local hospital & 71 & 45 \\
Clinic & 207 & 2 \\
\hline
\end{tabular}

suffer from limitations inherent to observational designs. There may be residual confounding effects yet to be corrected, and the causal relationships between profit status and patient outcome cannot be directly derived from an observational study design. Second, due to the personal information protection law in Taiwan, we are unable to directly access the facilities' length of ownership data and have to conduct online searches and telephone interviews for the information needed. Approximately $30 \%$ of the facilities refused to report information on their length of ownership, resulting in missing data and insufficient correction in model 3. Correction with geographical distribution and length of ownership (model 2+model 3) was also not performed because of the problem in model 3 . Similarly, due to limited access to more granular socioeconomic data of participants, more detailed geographical fixed effects of facilities and type of vascular access of each patient, adjustments regarding these factors could not be carried out. Third, most high-level medical facilities in Taiwan (table 7, medical centre and metropolitan hospital) are established as foundations and are deemed private NFP facilities. Nonetheless, some facilities were established as foundations for the sake of tax exemption and are de facto FP facilities. This finding cannot be properly addressed through statistical analysis. Lastly, immortal time bias is an important issue in the analysis of prevalence and patient survival, especially in our retrospective, long-term, nationwide population-based cohort study design. We could only decrease the impact of this bias using a time-dependent Cox regression model for the HR of mortality, and fortunately, a follow-up period of up to 7 years (figure 2) may alleviate the bias.

Our findings suggest that in contemporary HD settings in Taiwan, treatment at NFP dialysis facilities is associated with better outcomes. The result should be interpreted 
with caution, since the possibility of residual confounding effects and uncertainty of causal relations exist in the setting of an observational study. However, the favourable effects of private NFP facilities have been demonstrated in a recent unpublished meta-analysis from the USA. ${ }^{26}$ Studies also show shorter hospitalisation days or hospitalisation rates due to complications in NFP facilities. ${ }^{27} 28$ The effect of the profit status of HD facilities on patient prognosis is a widespread and longstanding problem that needs to be corrected. Government regulations should be made for the welfare of dialysis patients, and more research with a robust study design is needed to investigate the problem more thoroughly.

\section{Author affiliations}

${ }^{1}$ Division of Nephrology, Department of Internal Medicine, School of Medicine, College of Medicine, Taipei Medical University, Taipei, Taiwan

${ }^{2}$ Division of Nephrology, Department of Internal Medicine, Taipei Medical UniversityWanfang Hospital, Taipei, Taiwan

${ }^{3}$ TMU Research Center of Urology and Kidney (TMU-RCUK), Taipei Medical University, Taipei, Taiwan

${ }^{4}$ Division of Nephrology, Department of Internal Medicine, Taipei Medical UniversityShuang Ho Hospital, New Taipei City, Taiwan

${ }^{5}$ National Health Research Institutes, Institute of Population Health Sciences, Zhunan, Taiwan

${ }^{6}$ Division of Nephrology, Department of Internal Medicine, Taipei Medical University Hospital, Taipei, Taiwan

\section{Twitter Cai-Mei Zheng @Cai-Mei Zheng}

Acknowledgements We would like to thank Mr Kuang-wen Wang for analytical assistance.

Contributors $\mathrm{Y}-\mathrm{CL}, \mathrm{MSW}$ and $\mathrm{S}-\mathrm{YL}$ conceived and designed the experiments. Y-CL and S-YL performed the experiments. Y-CL, S-YL and C-CH analysed the data. Y-CL, MSW, S-YL, C-YC, M-YW and C-MZ contributed reagents/materials/analysis tools. S-YL and Y-CL wrote the manuscript. All authors read and approved the final manuscript.

Funding This study was supported by a grant from the Ministry of Science and Technology, ROC (MOST 106-2813-C-038-019-B) and Taipei Medical University Hospital (107TMU-TMUH-04).

Competing interests None declared.

Patient and public involvement Patients and/or the public were not involved in the design, or conduct, or reporting, or dissemination plans of this research.

Patient consent for publication Not required.

Ethics approval The independent Ethics Committee of Taipei Medical University approved this study (no. N202004151; principal investigator: C-MZ) and supervised it in accordance with the tenets of the Declaration of Helsinki (1975) and its later amendment (2013). The study fits all the applicable regulations for waiver of the informed consent.

Provenance and peer review Not commissioned; externally peer reviewed.

Data availability statement № data are available. № additional data available.

Open access This is an open access article distributed in accordance with the Creative Commons Attribution Non Commercial (CC BY-NC 4.0) license, which permits others to distribute, remix, adapt, build upon this work non-commercially, and license their derivative works on different terms, provided the original work is properly cited, appropriate credit is given, any changes made indicated, and the use is non-commercial. See: http://creativecommons.org/licenses/by-nc/4.0/.

ORCID iDs

Chung-Yi Cheng http://orcid.org/0000-0003-1816-7215

Yen-Chung Lin http://orcid.org/0000-0002-8981-8671

\section{REFERENCES}

1 Saran R, Robinson B, Abbott KC, et al. Us renal data system 2018 annual data report: epidemiology of kidney disease in the United States. Am J Kidney Dis 2019;73:A7-8.

2 Lin YC, Wu M-S, Wu M-Y, et al. Summary report of the 2019 annual report on kidney disease in Taiwan. Acta Nephrologica 2021;35:3-14

3 Chevreul K, Berg Brigham K, Durand-Zaleski I, et al. France: health system review. Health Syst Transit 2015;17:xvii:1-218.

4 Devereaux PJ, Schünemann HJ, Ravindran N, et al. Comparison of mortality between private for-profit and private not-for-profit hemodialysis centers: a systematic review and meta-analysis. JAMA 2002:288:2449-57.

5 Brooks JM, Irwin CP, Hunsicker LG, et al. Effect of dialysis center profit-status on patient survival: a comparison of risk-adjustment and instrumental variable approaches. Health Serv Res 2006;41:2267-89.

6 Foley RN, Fan Q, Liu J, et al. Comparative mortality of hemodialysis patients at for-profit and not-for-profit dialysis facilities in the United States, 1998 to 2003: a retrospective analysis. BMC Nephrol 2008;9:6.

7 Brunelli SM, Wilson S, Krishnan M, et al. Confounders of mortality and hospitalization rate calculations for profit and nonprofit dialysis facilities: Analytic augmentation. BMC Nephrol 2014;15:121.

8 Lin Y-C, Lin Y-C, Kao C-C, et al. Health policies on dialysis modality selection: a nationwide population cohort study. BMJ Open 2017:7:e013007.

9 Lien H-M, Chou S-Y, Liu J-T. Hospital ownership and performance: evidence from stroke and cardiac treatment in Taiwan. $J$ Health Econ 2008;27:1208-23.

10 Lin YC. Incidence and prevalence of ESRD in Taiwan renal registry data system (TWRDS): 2005-2012. Acta Nephrologica 2014;28:65-8.

11 Medical Care Act. Article 3. MOHW, Taiwan (R.O.C). amended date: 2020-01-15.

12 Code of practice on hospital accreditation and teaching hospital accreditation. MOHW, Taiwan (R.O.C). 2019.

13 Ministry of Interior, Taiwan (R.O.C.). Local Government Act, Article 4. Amended date: 2016-06-22: Laws \& Regulations Database of The Republic of China.

14 Nudelman PM, Andrews LM. The "value added" of not-for-profit health plans. N Engl J Med 1996;334:1057-9.

15 Woolhandler S, Himmelstein DU. When money is the mission--the high costs of investor-owned care. N Engl J Med 1999;341:444-6.

16 Herrera CA, Rada G, Kuhn-Barrientos L, et al. Does ownership matter? an overview of systematic reviews of the performance of private for-profit, private not-for-profit and public healthcare providers. PLoS One 2014;9:e93456.

17 Rosenthal G, Newbrander W. Public policy and private sector provision of health services. Int $J$ Health Plann Manage 1996;11:203-16.

18 Gray BH. For-Profit enterprise in health care. Institute of medicine. Washington, DC: National Academy Press, 1986.

19 Iszaid I, Hafizan AH, Muhamad J. Market failure in health care: a review. IJPHCS 2018:5:16-25.

20 Devereaux PJ, Heels-Ansdell D, Lacchetti C, et al. Payments for care at private for-profit and private not-for-profit hospitals: a systematic review and meta-analysis. CMAJ 2004;170:1817-24.

21 Friedman BS, Hattis PA, Bogue RJ. Tax exemption and community benefits of not-for-profit hospitals. Adv Health Econ Health Serv Res 1990;11:131-58

22 Lin W-H, Lin C-T, Chang H-F, et al. Financial performance of nonprofit hospitals in Taiwan. Journal of Information and Optimization Sciences 2011;32:419-31.

23 Hirth RA, Chernew ME, Orzol SM. Ownership, competition, and the adoption of new technologies and cost-saving practices in a fixedprice environment. Inquiry 2000;37:282-94.

24 Held PJ, García JR, Pauly MV, et al. Price of dialysis, unit staffing, and length of dialysis treatments. Am J Kidney Dis 1990;15:441-50.

25 Held PJ, Levin NW, Bovbjerg RR, et al. Mortality and duration of hemodialysis treatment. JAMA 1991;265:871-5.

26 Dickman S, Mirza R, Kandi M, et al. Mortality at for-profit versus not-for-profit hemodialysis centers: a systematic review and metaanalysis. Int J Health Serv 2021;51:371-8.

27 Dalrymple LS, Johansen KL, Romano PS, et al. Comparison of hospitalization rates among for-profit and nonprofit dialysis facilities. Clin J Am Soc Nephrol 2014;9:73-81.

28 Lee DKK, Chertow GM, Zenios SA. Reexploring differences among for-profit and nonprofit dialysis providers. Health Serv Res 2010;45:633-46. 